Original Research Article

\title{
A prospective observational pharmacovigilance study of adverse drug reaction monitoring in patients of tuberculosis receiving category $I$ and II treatment regimens at tertiary care hospital
}

\author{
Monali Raghunath Kale ${ }^{1}$, Mirza Shiraz Baig ${ }^{1 *}$, Avinash Lamb ${ }^{2}$
}

\begin{abstract}
${ }^{1}$ Department of Pharmacology ${ }^{2}$ Department of Chest and TB, Government Medical College and Hospital Aurangabad, Maharashtra, India
\end{abstract}

Received: 07 July 2018

Revised: 21 March 2019

Accepted: 27 March 2019

*Correspondence to:

Dr. Mirza Shiraz Baig,

Email: shirazdoctor@yahoo.com

Copyright: (C) the author(s), publisher and licensee Medip Academy. This is an openaccess article distributed under the terms of the Creative Commons Attribution NonCommercial License, which permits unrestricted noncommercial use, distribution, and reproduction in any medium, provided the original work is properly cited.

\begin{abstract}
Background: First line Anti-TB therapy with rifampicin, isoniazid, pyrazinamide, and ethambutol / streptomycin is very effective. However, major adverse reactions to antituberculous drugs can cause significant morbidity and mortality. One of the main reasons for non-adherence to anti-TB therapy (ATT) is ADRs, even under DOTS. Present study was carried out in tertiary care hospital. The objective of the study was to evaluate types and frequency of ADRs in intensive and continuation phase of category I and II Anti-TB medication.

Methods: A prospective observational study conducted in Department of TBChest and Medicine, Govt. Medical College, Aurangabad, Maharashtra, India. All the TB patients reporting at DOTS Center of institute were enrolled and monitored for ADRs. The causality and severity of the reactions were determined using Naranjo algorithm and Hartwig questionnaire.

Results: Total, $\mathrm{n}=241$ tuberculosis patients on DOTS therapy were enrolled for the study. Out of 241 patients, 17 were dropouts so 224 patients assessed for ADRs. 127 (56.69\%) developed adverse drug reactions. The higher numbers of ADRs were observed in age group 31-40 yrs followed by 21-30 yrs, ADRs were more common in men. Pulmonary TB $(73.66 \%)$ cases were more common than extra pulmonary TB. Majority of adverse drug reactions were Gastrointestinal (GI) problems (30.92\%), followed by Liver dysfunction and Hepatotoxicity $(20.39 \%)$ and skin problems $(17.10 \%)$. The causality of ADRs, in majority cases were found to be Probable (56.57\%). Around 19 patients require treatment interruption and most of the patients were managed with supportive medication without removing anti tubercular drug from regimen.

Conclusions: ADRs are major limiting factor for completion of drug therapy under RNTCP and occurrence of drug resistance which requires attention of all health care professionals.
\end{abstract}

Keywords: Adverse drug reactions, Antitubercular drugs, Causality assessment, Severity assessment

\section{INTRODUCTION}

It is in the very nature of drugs that they will cause adverse reactions. Antitubercular drugs just like other drugs used in clinical practice are not free from Adverse drug reactions. ${ }^{1}$ In disease like tuberculosis, the standard anti TB short course chemotherapy is the key component of the DOTS strategy. This requires continually taking drug combinations of different antitubercular drugs every alternative day for a prolonged period of time. ${ }^{2}$
Tuberculosis (TB) has been a major cause of suffering and death since time immemorial. Tuberculosis (TB) is one of the world's deadliest diseases, one third of the world's population is infected with TB. In 2015, 10.4 million people around the world became sick with TB disease. There were 1.4 million TB-related deaths worldwide India is the country with the highest burden of TB. The World Health Organization (WHO) statistics for 2015 give an estimated incidence figure of 2.2 million cases of TB for India out of a global incidence of 9.6 million. ${ }^{2-4}$ 
Administration of multiple drugs simultaneously is likely to create further problem of interaction of drugs. Adverse reactions are significant cause of morbidity and mortality and can affect adherence to treatment schedule and increase the risk of resistance and relapse of disease. Incidence of ADR being high with these drugs is resulting in more dropouts, change of regime and inadequate or incomplete treatment, all these contributing to emergence of multidrug resistant (MDR) and extensively drugresistant cases (XDR) strains increasing the morbidity and mortality. ${ }^{5}$ All antitubercular drugs can cause adverse drug reactions and may result in ADRs involving almost all systems in the body, including the gastrointestinal tract, liver, skin, nervous system, otovestibular apparatus and eyes. ${ }^{6}$

With the above background information, the present study aims to evaluate the adverse drug reactions and incidence of treatment discontinuation in relation to ADR in patients receiving the category $I$ and II anti-TB regimens under RNTCP in a tertiary care hospital.

\section{Aims and objectives}

- Adverse drug reaction monitoring in patients of Tuberculosis (TB) receiving category I and II treatment at Tertiary Care Hospital.

- Identification of types and frequency of adverse drug reactions in Intensive and continuation phase of Category I and II Anti-TB medication.

- To evaluate the incidence of treatment discontinuation in relation to ADRs.

- To assess causality and severity of the reported adverse drug reactions.

\section{METHODS}

The present study was a prospective, observational, open label, longitudinal, descriptive clinical study.

\section{Procedure}

The patients receiving anti-TB (AKT) medications as per RNTCP schedule come under category I and II were enrolled in Govt. Medical College Aurangabad.

Data was collected from January 2015 to June 2016. Each patient will be followed up on 2 monthly basis (day 0,2 months, 4 months and 6 monthly and end of therapy) and will be asked questions regarding possible adverse drug reactions of the drug which are prescribed to them. In between the 2 monthly follow up in OPD, telephonic questioning regarding adverse drug reactions will be asked on the fifth day of every month. Anticipated ADRs will be identified and assessed. The causality of adverse drug reactions will be assessed as per Naranjo's causality assessment scale, for severity of the adverse drug reactions as per Modified Hartwig-Siegel Scale. At the end of the study, these adverse event records will be analyzed and statistically interpreted.

\section{Inclusion criteria}

- $\quad$ Patient of either sex of age more than 18 years - 45 years with tuberculosis.

- Diagnosed cases of pulmonary/extra pulmonary TB, enrolled under RNTCP program receiving category I / category II medications.

- Agreed to adhere tuberculosis treatment regime prescribed.

- Patient who provide written informed consent and ready to give follow up

\section{Exclusion criteria}

- Complicated and severe cases of TB required additional poly therapy / already received additional MDR - TB drugs.

- History of patients receiving ART treatment.

- Patients with deranged liver and kidney function tests.

- History of patient suffering from any other chronic disease condition requiring any concomitant medication.

- Patients those were transferred to MDR/XDR$\mathrm{TB} /$ whose diagnosis was changed.

- Not ready to give informed consent.

- Not ready to give follow up.

\section{Following parameters were studied}

- Incidence of adverse drug reactions in anti-TB (AKT) agents.

- Severity of adverse drug reaction using Modified Hartwig-Siegel scale.

- Causality of adverse drug reaction using Naranjo's scale.

\section{RESULTS}

A total number of $n=224$ patients who were on DOTS therapy were included in our study. Male patients were 149 $(66.51 \%)$ and $75(33.48 \%)$ were female.

Table 1: Demographic profile of patients receiving anti tubercular drugs.

\begin{tabular}{|llll|}
\hline \multirow{2}{*}{ Parameters } & Number & Percentage \\
\cline { 2 - 4 } & Male & 149 & 66.51 \\
\hline \multirow{2}{*}{$\begin{array}{l}\text { Age } \\
\text { group } \\
\text { (in years) }\end{array}$} & Female & 75 & 33.48 \\
\cline { 2 - 4 } & $<20$ & 33 & 14.73 \\
\cline { 2 - 4 } & $21-30$ & 72 & 32.14 \\
\hline Type of & $41-45$ & 82 & 36.60 \\
TB & Pulmonary & 165 & 73.66 \\
\hline Type of & Extra-pulmonary & 59 & 26.33 \\
\cline { 2 - 4 } DOTS & Category I & 178 & 79.46 \\
\hline
\end{tabular}


Table 2: Incidence of adverse drug reactions.

\begin{tabular}{|lll|}
\hline Adverse drug reactions & $\begin{array}{l}\text { No. of } \\
\text { patients }\end{array}$ & $\begin{array}{l}\text { Percentage } \\
(\%)\end{array}$ \\
\hline Gastrointestinal & 47 & 30.92 \\
\hline Nausea & 11 & 7.23 \\
\hline Vomiting & 09 & 5.92 \\
\hline Anorexia & 03 & 1.97 \\
\hline Constipation & 14 & 9.21 \\
\hline Diarrhea & 04 & 2.63 \\
\hline Gastritis & 06 & 3.94 \\
\hline Neurological & 19 & 12.50 \\
\hline Headache & 07 & 4.60 \\
\hline Burning sensation & 03 & 1.97 \\
\hline Loss of sensation & 05 & 3.28 \\
\hline Psychosis & 02 & 1.31 \\
\hline Dizziness & 02 & 1.31 \\
\hline Liver and biliary system & 31 & 20.39 \\
\hline Hepatitis & 19 & 12.50 \\
\hline Deranged LFT & 12 & 7.89 \\
\hline Skin & 26 & 17.10 \\
\hline Itching & 15 & 9.86 \\
\hline Rash & 06 & 3.94 \\
\hline Allergic skin reaction & 05 & 3.28 \\
\hline Musculoskeletal & 4 & 2.63 \\
\hline Joint pain & 04 & 2.63 \\
\hline Muscle wasting & 00 & 00 \\
\hline Vision defect & 02 & 1.31 \\
\hline Impaired visual acuity & 01 & 0.65 \\
\hline Color discrimination & 01 & 0.65 \\
\hline Auditory defect & 02 & 1.31 \\
\hline Decreased hearing & 01 & 0.65 \\
\hline Tinnitus and vertigo & 01 & 0.65 \\
\hline Metabolic & 06 & 3.94 \\
\hline Hyperglycemia & 06 & 3.94 \\
\hline Urinary System & 03 & 1.97 \\
\hline Dysuria & 02 & 1.31 \\
\hline Deranged RFT & 01 & 0.65 \\
\hline Blood & 01 & 0.65 \\
\hline Bleeding tendencies & 01 & 0.65 \\
\hline Other & 11 & 7.23 \\
\hline Fever & 06 & 3.94 \\
\hline Gen. weakness & 05 & 3.28 \\
\hline & & \\
\hline
\end{tabular}

Patients of different age group ranging from 18-45 years were reported in the study. 33 patients were under 20 years of age $(14.73 \%)$ followed by 72 resides in the age of $21-30$ (32.14\%), 31-40 of 82 patients $(36.60 \%)$. Rest were in 41 45 years age group $(16.51 \%)$ (Table 1$)$. The patients of TB in the study were divided according to their type of TB, like pulmonary $(165 / 73.66 \%)$ and extra pulmonary (59/26.33\%). Out of 224 patients, 178 (79.46\%) were from patients on category I of the DOTS therapy, followed by 46 (20.53\%) from category II.

Out of these 224 patients 127 patients developed 152 ADRs of various types (Table 2). Among the 152 reported ADRs, most were observed in males $(84 / 55.26 \%)$ and remaining (43/28.28\%) were females. The overall incidence of ADRs was $56.69 \%$. ADRs in this study were categorized according to the systems affected like gastrointestinal system, skin, neurological system and other systems like vestibular, muscle etc. Majority of ADRs were related to gastrointestinal system (47 cases) followed by liver and biliary system (31 cases), Skin (26 cases), neurological system (19 cases), other systems (29 cases). Nausea and vomiting were the most common ADR $(13.15 \%)$ followed by hepatitis $(12.50 \%)$, skin itching $(9.86 \%)$.

It does appear that with anti TB drugs used in this study the rate of ADRs increases with increased age. The main action taken in patients with detected ADR was withhold/discontinuation of drug regimen $(8.48 \%)$. The action mainly was taken when hepatotoxicity was detected.

The causality assessment of ADRs revealed that 4 (2.63\%) cases were detected as Definite, $62(40.78 \%)$ as possible and $86(56.57 \%)$ as probable reactions. The Severity assessment of ADRs revealed that 102 (67.10\%) cases were mild, 50 (32.89\%)were Moderate and no any sever ADR observed.

\section{Naranjos casuality scale}

AS per Naranjos casuality Scale $56.57 \%$ ADRs were Probable, 40.78 were Possible and $2.63 \%$ ADR were definite/unlikely.

Table 3: Showing causality of ADRs induced by anti TB drugs according to Naranjo algorithm.

\begin{tabular}{|lll|}
\hline Type & No. of patients & Percentage \\
\hline Probable & 86 & 56.57 \\
\hline Possible & 62 & 40.78 \\
\hline Definite & 4 & 2.63 \\
\hline Total & 152 & 100 \\
\hline
\end{tabular}

Table 4: Showing severity of ADRs induced by anti TB drugs according to modified Hartwig-Sigel scale.

\begin{tabular}{|lll|}
\hline Type & No. of patients & Percentage \\
\hline Mild & 102 & 67.1 \\
\hline Moderate & 50 & 32.89 \\
\hline Severe & 0 & 0 \\
\hline Total & 152 & 100 \\
\hline
\end{tabular}

\section{Modified Hartw-Sigsigel scale - severity scale}

$67.10 \%$ of the cases were mild, $32.89 \%$ were moderate and no any sever ADR observed.

\section{DISCUSSION}

Total 152 ADRs were observed in 127 patients with age group ranging from 18-45 years. Highest number of ADRs were observed with age group 31-40 (37\%), followed by 
21-30 (33.07\%). Similar observations were found in other studies. Which showed that maximum ADRs between age group of 31-40 years. ${ }^{1}$ Whereas, another study showed that ADRs was more prevalent with number of patients more in the 31-40 years age group. ${ }^{7}$

As per gender distribution in present study, 84 (66.14\%) are men and $43(33.85 \%)$ women. The high incidence rate of ADR in males can be justified on the basis of their gender specific additional sensitivity to the effect of drugs as compared to females. But in present study, males developed more ADRs and it could be because more numbers of males were included in study. Similar results of higher incidence of ADR in male tuberculosis patients were observed. Another study showed that occurrence of ADRs was more in male patients $(45,63 \%)$ as compared to females $(27,37 \%){ }^{8,9}$ Another study showed that higher numbers of ADRs were observed in males (68.81\%) and the remaining $(31.18 \%)$ was observed in female. Another finding showed that adverse drug reactions occur mainly in young and middle aged adults and is twice common in men i.e. ADR observed in males $(15 / 78.9 \%)$ and remaining $(4 / 21.1 \%)$ were females. ${ }^{10}$ Several studies in human pharmacology have described differences in pharmacokinetics and in drug response, toxicity between males and females. Differences in weight and body mass index between men and women may be playing an important role.

In the present study out of total 224 patients, $176(79.46 \%)$ patients are registered under category I while remaining 48 $(20.53 \%)$ are under category II (Table 3), in which Occurrence of ADRs was significantly more in patients suffering from category I TB:90 patients $(70.86 \%)$ as compared to category II: 37 (29.13\%). Similarly, the higher incidence of ADR among category I was shown in category I TB:31 (43\%) as compared to category II. Another study observed that, among 93 patients with ADRs 70 patients (75.26\%) were from category I and 23 patients $(24.73 \%)$ were from category II..$^{8,9}$

In present study total 224 patients are enrolled in study out of which majority of patients have pulmonary tuberculosis $165(73.66 \%)$ and remaining 59 patients $(26.33 \%)$ are of Extra-pulmonary tuberculosis (Table 4). Similar findings were seen in studies where pulmonary TB $(55.18 \%)$ was more common than extra pulmonary TB. Another study reported that out of total 102 cases, $60.8 \%$ were of pulmonary TB while rest $39.2 \%$ were of extra - pulmonary TB. ${ }^{6,8}$

In the present study, the incidence of ADR associated with anti-tubercular drugs in TB patients under DOTS are observed as $56.69 \%$ i.e. 127 out of 224 patients. Total number of adverse reactions developed in 127 patients were 152 . Almost similar reporting was noted by different studies. ${ }^{7,11,12}$

The most common Adverse reactions observed in current study were GI system related $30.92 \%$, followed by liver dysfunction and hepatotoxicity 20.39 , skin $17.10 \%$, central and peripheral nervous system $12.50 \%$, musculoskeletal $2.63 \%$, metabolic $3.94 \%$, vision defect $1.31 \%$ and hearing defect $1.31 \%$, urinary system $1.97 \%$, bleeding tendency $0.65 \%$ and Other $7.23 \%$. Similar results were noted in studies, with most common being GI system related $(38.7 \%)$, followed by skin problems (29\%), Liver dysfunction $(9.7 \%)$, hepatotoxicity $(6.5 \%)$ and hematological diathesis $(3.2 \%)$.

One case each was noted of visual and hearing problems, hyperuricemia and joint pain. 6 Similar observations were also noted in another study where majority of adverse drug reactions were GI related problem $(38.01 \%)$, followed by skin reactions $(30.48 \%)$ then hepatotoxicity (14.28\%). Authors have observed that most frequent system-organ class affected by ADRs was liver and biliary system (37\%). Hepatitis was observed in $21(25.3 \%)$ and GI system (21\%). Multiple drug therapy was noticed to be a major pre-disposing factor for developing GI problem.

Another study noted that the most commonly involved system was hepatic and biliary system $(53.33 \%)$ followed by gastrointestinal (GI) system $(51.11 \%)$, dermatological (28.88\%) CNS and PNS (22.22\%), fever and flu-like syndrome $(13.33 \%)$, optic neuritis and blurred vision $(11.11 \%)$ and metabolic system $(11.11 \%)$, renal toxicity $(4.44 \%)$, gout and arthralgia $(4.44 \%)$, hematological toxicities $(2.22 \%){ }^{11-13}$

In present study most common ADR developed in alcoholics was hepatitis and disturbed liver transaminases. Similar findings were observed and a significant association between alcohol addiction with development of ADR was noted. ${ }^{2,8}$

In present study withhold/withdrawal of RNTCP drugs due to adverse drug reactions was seen in 19 patients $(8.48 \%)$ with hepatotoxicity and deranged liver enzyme levels more than 5 times the baseline level. Drugs withhold during hepatitis are $\mathrm{H}$ (isoniazid), $\mathrm{R}$ (rifampicin) and $\mathrm{Z}$ (pyrazinamide) for 2-3 weeks till patient cure from symptoms and again continuation of Antitubercular drugs with close monitoring of Liver function test observed in above all patients.

To strengthen the validity of the findings of the study, causality assessment was made for individual cases by using Naranjo's scale. Present study showed that 86 (56.57\%) ADRs have Probable cause, while 62 (40.78\%) ADRs have possible cause and $4(2.63 \%)$ of them are definite cases. Similar observations were found in a study, wherein $58.2 \%$ scored probable, $31.86 \%$ were of possible score, whereas $9.8 \%$ were in definite score category. Another study reveals that 7 (8.6) cases were detected as certain, $35(43.2 \%)$ as possible and $39(48.2 \%)$ as probable reactions. Similar finding was also notifying in a study where majority of the reactions were probable $(68.57 \%)$, followed by possible $(20 \%)$. There were no definite reactions. ${ }^{8,11,13}$ 
The majority of ADRs were found to be mild and well tolerated by the patients. None of ADR found to be of severe type or no intensive care admission or no death recorded due to any ADR. All the mild ADRs were treated with symptomatic treatment.

Preventability was assessed by using modified HartwigSigel scale. Present study result found that out of total ADRs, $67.10 \%$ were mild, $32.89 \%$ were moderate while no any ADR found to be severe according to scale distribution. Findings in a study showed that $33(68.57 \%)$ were moderate, $72(31.42 \%)$ were mild reactions and there were no severe reactions reported. Another study showed that, $68.88 \%$ cases of mild grading, $31.11 \%$ of moderate, and no case of severe grading were reported in the study duration. Yet another study indicated that most of the ADRs detected had severity in level $1(38.2 \%)$ and $4 \mathrm{a}$ $(34.5 \%){ }^{8,11,13}$

\section{CONCLUSION}

Adverse Drug Reactions (ADRs) are encountered commonly in the daily therapeutics. In addition to the obvious morbidity and mortality which are caused by them, they also cause an economic burden on the health care system of human beings. Adverse drug reactions are preventable if the health care professional pays close attention to the details of the adverse events, following drug administration.

The present study of identification and assessment of adverse drug reaction in patients of Tuberculosis (TB) receiving category I and II treatment regimens showed. This study showed that about $56.69 \%$ people who received DOTS therapy developed different type of ADRs during the intensive phase of the treatment. Maximum number of ADRs observed in age group 31-40 years followed by 21 30years which are more common in men. Pulmonary type and category I class of Tuberculosis patients are most commonly observed with occurrences of adverse drug reactions. Addictions shows significant association with development of ADR. Most common adverse reaction observed were GI system related followed by Liver dysfunction and hepatotoxicity, skin problems. In present study withheld of RNTCP drugs due to adverse drug reactions is observed. A majority of ADRs is probable in causality assessment and more of them are seems to be preventable. Most of the ADR observed are of mild to moderate reactions but not reaches up to the severe reaction. Authors conclude that in treating cases of Tuberculosis Adverse drug reaction monitoring is helpful for better outcome of the treatment regimens.

\section{ACKNOWLEDGEMENTS}

Authors would like to would like to thank the Department of ENT and Ophthalmology, Govt. Medical College, Aurangabad (MS) INDIA for their kind help in analysis of ADRs. Authors would also like to acknowledge the generous support from all concerned in the Chest TB Department of GMC, Aurangabad, India.

Funding: No funding sources

Conflict of interest: None declared

Ethical approval: The study was approved by the Institutional Ethics Committee

\section{REFERENCES}

1. Sinha K, Marak IT, Singh WA. Adverse drug reactions in tuberculosis patients due to directly observed treatment strategy therapy: Experience at an outpatient clinic of a teaching hospital in the city of Imphal, Manipur, India. J Assoc Chest Physicians. 2013;1(2):50.

2. Kurniawati F, Azhar S, Sulaiman S, Gillani SW. Adverse Drug Reactions of Primary Anti-tuberculosis Drugs Among Tuberculosis Patients Treated in Chest Clinic. Int J Pharm Life Sci. 2012;3(1):1331-8.

3. Hema NG, Bhuvana KB, Virupaksha HM. Critical assessment of adverse drug reactions to antitubercular drugs in a government teaching hospital. Intern J Basic Med Sci. 2013;5(5):60-7.

4. Bhargava A, Pinto L, Pai M. Mismanagement of tuberculosis in India: Causes, consequences, and the way forward. Hypothesis J. 2011;9(1):15-9.

5. Xia YY, Liu FY, Wang XM, Yuan YL, Tu DH, Chen $\mathrm{YX}$, et al. Design of the anti-tuberculosis drugs induced adverse reactions in China National Tuberculosis Prevention and Control Scheme Study (ADACS). BMC Public Health. 2010 Dec;10(1):267.

6. Nanda GS, Singh H, Sharma B, Arora A. Adverse Reactions Due to Directly Observed Treatment Short Course Therapy: An Indian Prospective Study. Int Arch Integrated Med. 2016;3(1):6-12.

7. Siddiqui S, Baig MMA, Jaffer S, Ansari SFR. Study on prevalence of adverse drug reactions in patients suffering from tuberculosis in a tertiary care hospital. Int J Pharma Pharmaceut Sci. 2016;8(8):375-7.

8. Athira B, Manju CS, Jyothi E. A study on adverse drug reactions to first line anti-tubercular drugs in DOTS therapy. Int J Pharmacol Clin Sci. 2015;4:7-11.

9. Dedun A, Patel D. A Profile of Adverse Effects of Anti-Tubercular Drugs. GCSMC J Med Sci. 2016;5(1):37-41.

10. Mishra S, Jena M, Jena B, Mishra SS. A Study of AntiTubercular Drug Induced Adverse Reactions in Patients Attending Pulmonary Medicine Department of a Tertiary Care Teaching Hospital. Int J Pharm Sci Rev Res. 2013;21(2): 308-11.

11. Gholami K, Kamali E, Hajiabdolbaghi M, Shalviri G. Evaluation of anti-tuberculosis induced adverse reactions in hospitalized patients. Pharma Pract. 2006;4(3):134.

12. Sreekanth AS. A Pharmacovigilance Study on Antitubercular Therapy in the Department of Pulmonary Medicine at a Tertiary Care Hospital. J Dental Med Sci. 2015;14(8):2279-861. 
13. Verma R, Gr M, Shrivastava AK, Pathak P. Adverse Drug Reactions Associated with First Ğ Line Anti Ğ Tubercular Drugs in a Tertiary Care Hospital of Central India: a Study of Clinical Presentations, Causality, and Severity. Asian J Pharm Clin Res. 2014;7(5):7-10.
Cite this article as: Kale MR, Baig MS, Lamb A. A prospective observational pharmacovigilance study of adverse drug reaction monitoring in patients of tuberculosis receiving category I and II treatment regimens at tertiary care hospital. Int J Basic Clin Pharmacol 2019;8:875-80. 